\title{
Impacts of Human Activities and Climate Change on Freshwater Fish
}

\author{
Pietro Volta ${ }^{1, *(1)}$ and Erik Jeppesen ${ }^{2,3,4,5}$ \\ 1 Water Research Institute, IRSA-CNR, L.go Tonolli 50, 28922 Verbania, Italy \\ 2 Department of Ecoscience, Aarhus University, 8600 Silkeborg, Denmark; ej@ecos.au.dk \\ 3 Sino-Danish Centre for Education and Research, University of Chinese Academy of Sciences, \\ Beijing 100049, China \\ 4 Limnology Laboratory, Department of Biological Sciences and Centre for Ecosystem Research and \\ Implementation, Middle East Technical University, Ankara 06800, Turkey \\ 5 Institute of Marine Sciences, Middle East Technical University, Mersin 33731, Turkey \\ * Correspondence: pietro.volta@cnr.it
}

Citation: Volta, P.; Jeppesen, E. Impacts of Human Activities and Climate Change on Freshwater Fish. Water 2021, 13, 3068.

https://doi.org/10.3390/w13213068

Received: 28 October 2021

Accepted: 29 October 2021

Published: 2 November 2021

Publisher's Note: MDPI stays neutral with regard to jurisdictional claims in published maps and institutional affiliations.

Copyright: (C) 2021 by the authors. Licensee MDPI, Basel, Switzerland. This article is an open access article distributed under the terms and conditions of the Creative Commons Attribution (CC BY) license (https:/ / creativecommons.org/licenses/by/ $4.0 /)$.
Fish are the vertebrates that count most species on Earth. Compared with terrestrial tetrapods, fish are at the base of the evolutionary scale of vertebrates where they occupy the oldest position (ca. 400 million years). Fish hold an astonishing variability in shape, and during the long history of evolution they have colonised very diverse and remote habitats. Despite the huge water volume of seas (ca. $97 \%$ of the total amount of water available on Earth), only $49 \%$ of the known fish species live in the sea, whilst the remaining $51 \%$, live in lakes and rivers that constitute only $0.0093 \%$ of the water on Earth. Despite their ecological, economic and social importance, freshwater fish all around the world are threatened by multiple pressures as a consequence of the rapid development of modern society during the last two centuries. Pressures include eutrophication, chemical pollution, overfishing, water abstraction and river morphology alteration, as well as novel emerging contaminants and spread of invasive alien species. Finally, climatic changes, characterised by increased drought in some parts of the world, extreme events and warming often boost the negative impacts of the aforementioned pressures on fish communities in both lakes and rivers.

The responses of fish community structure to lake eutrophication have been intensively investigated, especially in Europe, while only a few studies are still available from subtropical lakes. In [1] the fish community structure in 36 lakes located in the Yangtze River basin, covering a wide nutrient gradient, was investigated. Fish catches increased significantly with lake productivity and a high abundance, biomass, and proportion of zooplanktivorous fish led to a high predation pressure on zooplankton, with consequent negative impacts on lake ecosystems through cascading effects. The small-sized zooplanktivorous Sijiao (Toxabramis swinhonis) and the omniplanktivorous sharpbelly (Hemiculter leucisculus) were the most dominant species in these study lakes, and this may be so in other subtropical lakes along the Yangtze River as well. The authors suggest that for the management and restoration of shallow subtropical lakes, not only large fish but also small fish occurring in high abundance should be considered.

Climate change has also been shown to affect freshwater fish communities in both rivers and lakes. In south Mediterranean countries, the effect of climatic changes including warming and severe drought periods can lead to decreased ecological connectivity. Ref. [2] analysed the changes in the distribution of three small-sized endemic fish species, namely Padogobius nigricans, Squalius lucumonis and Telestes muticellus, in the Tiber River basin (Italy), within a proven period of climate warming, in terms of increasing water temperature and droughts. A multivariate analysis conducted using fish and environmental data collected at 117 sites over the years 1990-2017 showed that S. lucumonis and T. muticellus shifted their distributions upstream, likely in order to reach their thermal optimum. Conversely, P. nigricans did not move upstream since the species is characterised by limited vagility 
and thus has low dispersal capability at high river fragmentation. Elevation and river barriers seem to play a key role in extirpation and colonisation processes: for S. lucumonis and T. muticellus, the extinction probability decreased with increasing altitude, while for P. nigricans the colonisation probability decreased with an increasing degree of river fragmentation. These results highlight how species-specific dispersal ability can lead to varying degrees of adaptability to climate change.

The interaction between climate change (water warming and extreme events) and eutrophication may have detrimental effects on cold water fish species of northern European lakes as well. Ref. [3] show that extreme weather events such as heat waves in summer and non-permanent ice-cover in winter in consecutive years may have long-lasting harmful effects on the population abundance of cool-water fish species such as vendace (Coregonus albula) whose eggs usually develop during ice cover in north-temperate lakes. In particular, they identified that the hot summer of 1988, which was accompanied by a severe cyanobacterial bloom and extensive fish kill, and the subsequent non-permanent ice cover and early ice-offs in 1989 and 1990 in Lake Peipsi were the main reasons for the disappearance of vendace from catches in 1991. Moreover, a negative correlation appeared between catches of the predatory pikeperch (Sander lucioperca) and vendace. These results indicate that predation pressure as well as fish habitat degradation caused by lake eutrophication contributed to the instability of the vendace population too.

Disentangling the effects of climate change on nature is one of the main challenges facing ecologists nowadays. Space-for-time substitution studies (SFTS) are often used to unravel climate effects on lake biota; however, results from continental lakes are potentially confounded by biogeographical and evolutionary differences, also leading to an overall higher fish species richness in warm lakes. Such differences may not be found in lakes on remote islands where naturally fish-free lakes have been subjected to stocking only during the past few hundred years. Ref. [4] studied 20 species-poor lakes located in two remote island groups with contrasting climates but similar seasonality. As for mainland lakes, the mean body size of fish in the warmer lakes was overall smaller and the phytoplankton per unit of phosphorus higher. The $\delta^{13} \mathrm{C}$ carbon range for basal organisms, and for the whole food web, appeared wider in colder lakes. In contrast to previous works in continental fresh waters, Layman metrics of the fish food web were similar between the two climatic regions. These results from insular systems provide further evidence that ambient temperatures drive, at least partially, the changes in fish size structure and the cascading effects found along latitude gradients in lakes.

The great fragmentation of freshwater environments, as well as the isolation that occurred during the Earth's evolution, led to remarkable species differentiation and endemism. Peri-mediterranean regions are key areas for biodiversity due to their role as a refugium during glaciations. However, multiple pressures are eroding native biodiversity, leading to fish community homogenisation and endemic species losses. Ref. [5] provide an updated review on the current status of endemic fish species from main lakes of Turkey, a well-known hotspot for fish biodiversity worldwide, including major threats affecting fish assemblages. Sixty two endemic fish species were reported to occur in the 37 Turkish lakes included in the study. The presence of non-native and invasive species, agricultural activities, climatic drought and decreasing water level were found to be the key threats affecting the fish communities in these lakes.

Knowledge of the ecological features of invasive alien species is crucial for their effective management, especially in newly invaded ecosystems. Ref. [6] provided the first data on the diet and habitat distribution of the invasive European catfish Silurus glanis in Lake Maggiore, a large and deep lake located in North Italy. Winter sampling showed that the catfish inhabits both benthic and pelagic habitats. The NPUE (Number Per Unit Effort, $\mathrm{n}$. ind. $\mathrm{m}^{-2}$ ) and BPUE (Biomass Per Unit Effort, $\mathrm{g} \mathrm{m}^{-2}$ ) of catfish captured by gill nets were generally higher in littoral than in pelagic habitats, but the catfish had, on average, larger sizes in pelagic habitats. The pelagic catfish specialised their diet 
exclusively on three prey fish (coregonids, shad and roach), while the diet of littoral catfish was more variable and dominated by crayfish, perch and roach.

Freshwaters worldwide and their fauna are threatened also by various types of emerging contaminants that accumulate in fish in different ways (e.g., diet) and potentially are transferred to top predators and humans. Microplastics (MPs) have received increasing attention in the last decade and are now considered among the most concerning emerging pollutants in natural environments. Ref. [7] analysed the consumption of plastics debris by the fish communities in streams of Uruguay with two contrasting types of land use (urbanised and extensive ranching). The stomach and intestinal contents of 309 individuals of 29 species were analysed. A total of 373 plastic items were found, of which the majority were fibres (318). A significant difference was found between the percentage of individuals that consumed plastics debris between both systems, but no difference was found in the average ingested debris per individual. Although there were differences between the analysed sites, significant contamination in streams far from urbanisation was also observed. The problem of plastics pollution was also considered by the work of [8], who reviewed the current knowledge of MPs ingestion by wild freshwater fish with a focus on the identification of possible factors leading to the ingestion of MPs and the consequences on fish health; 257 species of freshwater fishes from 32 countries have been documented to ingest MPs. MPs ingestion was found to increase with rising level of urbanisation, but a direct correlation with MPs concentration in the surrounding water was not identified. MPs were found in the digestive tract and also in the gills, and there is evidence that MPs can translocate to different tissues of the organism. Strong evidence, therefore, exists that MPs may represent a serious risk for ecosystem, and are a direct danger for human health. Moreover, toxicological effects have also been highlighted in wild catches, demonstrating the importance of this problem, which emphasizes the need for laboratory experiments that are more representative of the environmental situation.

While the degradation of freshwaters is a frequent topic of numerous studies, the restoration of degraded freshwater environments is not so common in the scientific literature despite the crucial role it has for improving biodiversity and preserving ecosystem services. Rocky reefs provide important spawning and refuge habitats for lithophilic spawning fishes. However, many reefs have been lost or severely degraded through anthropogenic effects like dredging, channelisation or sedimentation. Constructed reefs have been used to mitigate these effects in some systems, but the reefs are also subject to degradation that may warrant custodial maintenance. Monitoring and maintenance of natural or constructed spawning reefs are not common; therefore, few methodologies have been developed to test the effectiveness of such tools. Ref. [9] conducted a literature review to assess the available information on the maintenance of rocky spawning habitats used by lithophilic fishes, and 54 rocky spawning habitat maintenance projects were identified, most of which aimed to improve fish spawning habitats through the addition of spawning substrate $(n=33)$ or cleaning of substrate $(n=23)$. However, in comparison to shallow riverine studies focused on salmonids, little information was found on deep-water reefs, marine reefs or other fish species, indicating the need for more applied research studies in this field in the future.

Author Contributions: Conceptualization, writing—original draft preparation, P.V.; writing—review and editing, P.V., E.J. All authors have read and agreed to the published version of the manuscript.

Funding: E.J. was supported by the TÜBITAK program BIDEB2232 (project118C250). P.V. was supported by LIFE15 NAT/IT/0000823 IdroLIFE Project.

Acknowledgments: We thank Anne Mette Poulsen for valuable editions.

Conflicts of Interest: The authors declare no conflict of interest. 


\section{References}

1. Yu, J.; Zhen, W.; Kong, L.; He, H.; Zhang, Y.; Yang, X.; Chen, F.; Zhang, M.; Liu, Z.; Jeppesen, E. Changes in Pelagic Fish Community Composition, Abundance, and Biomass along a Productivity Gradient in Subtropical Lakes. Water 2021, 13, 858. [CrossRef]

2. Carosi, A.; Padula, R.; Ghetti, L.; Lorenzoni, M. Endemic Freshwater Fish Range Shifts Related to Global Climate Changes: A Long-Term Study Provides Some Observational Evidence for the Mediterranean Area. Water 2019, 11, 2349. [CrossRef]

3. Kangur, K.; Ginter, K.; Kangur, A.; Kangur, P.; Möls, T. How Did the Late 1980s Climate Regime Shift Affect Temperature-Sensitive Fish Population Dynamics: Case Study of Vendace (Coregonus albula) in a Large North-Temperate Lake. Water 2020, $12,2694$. [CrossRef]

4. Vidal, N.; Amsinck, S.L.; Gonçalves, V.; Azevedo, J.M.N.; Johansson, L.S.; Christoffersen, K.S.; Lauridsen, T.L.; Søndergaard, M.; Bjerring, R.; Landkildehus, F.; et al. Food Webs and Fish Size Patterns in Insular Lakes Partially Support Climate-Related Features in Continental Lakes. Water 2021, 13, 1380. [CrossRef]

5. Giannetto, D.; Innal, D. Status of Endemic Freshwater Fish Fauna Inhabiting Major Lakes of Turkey under the Threats of Climate Change and Anthropogenic Disturbances: A Review. Water 2021, 13, 1534. [CrossRef]

6. De Santis, V.; Volta, P. Spoiled for Choice during Cold Season? Habitat Use and Potential Impacts of the Invasive Silurus glanis L. in a Deep, Large, and Oligotrophic Lake (Lake Maggiore, North Italy). Water 2021, 13, 2549. [CrossRef]

7. Vidal, C.; Lozoya, J.P.; Tesitore, G.; Goyenola, G.; Teixeira-de-Mello, F. Incidence of Watershed Land Use on the Consumption of Meso and Microplastics by Fish Communities in Uruguayan Lowland Streams. Water 2021, 13, 1575. [CrossRef]

8. Galafassi, S.; Campanale, C.; Massarelli, C.; Uricchio, V.F.; Volta, P. Do Freshwater Fish Eat Microplastics? A Review with A Focus on Effects on Fish Health and Predictive Traits of MPs Ingestion. Water 2021, 13, 2214. [CrossRef]

9. Baetz, A.; Tucker, T.R.; DeBruyne, R.L.; Gatch, A.; Höök, T.; Fischer, J.L.; Roseman, E.F. Review of Methods to Repair and Maintain Lithophilic Fish Spawning Habitat. Water 2020, 12, 2501. [CrossRef] 